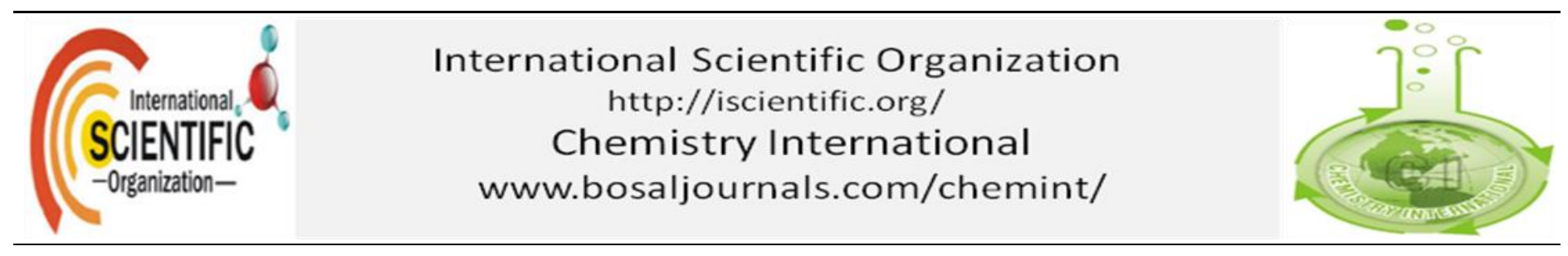

\title{
Synthesis and characterization of alkyl polyglucoside surfactant: A pilot tool to industrial applications
}

\author{
Chidi Obi, Precious Valentine Aliba and Godson Ndubuisi Iwuoha*
}

\begin{abstract}
Department of Pure and Industrial Chemistry, Faculty of Science, University of Port Harcourt, Rivers State, Nigeria
\end{abstract}
*Corresponding author's E. mail: holygodson@yahoo.com

A R T I C L E I N F O

\section{Article type:}

Research article

Article history:

Received January 2021

Accepted April 2021

July 2021 Issue

Keywords:

Akyl polyglucoside

Synthesis

Characterization

Critical micelle concentration

Applications

A B S T R A C T

In this study, alkyl polyglucoside surfactant was synthesized and the critical micelle concentration (CMC) was determined. The synthesized product was quantified using Gas Chromatography-Mass Spectroscopy (GC-MS). The CMC of the surfactant was evaluated using UV-visible Spectrophotometer. The critical micelle concentration (CMC) value was obtained from the sharp break in the plot of absorbance measurements versus surfactant concentration. The critical micelle concentration (CMC) of the surfactant was found to be $0.50 \mathrm{~mol} / \mathrm{dm}^{3}$. This result showed a precise value for the CMC of non-ionic surfactant; since the value of the $\mathrm{CMC}$ obtained was lower than the stock solution of the surfactant prepared. The standard change in Gibbs free energy of the micelle $\left(\Delta \mathrm{G}^{\circ} \mathrm{Cмc}\right)$ showed that the process was feasible and spontaneous having the value of $-1.716 \mathrm{~kJ} / \mathrm{mol}$. This study recommends that akyl polyglucoside should be widely used for both domestic and industrial processes in view of the environmentally friendly nature, which are safe to use partially.

(C) 2021 International Scientific Organization: All rights reserved.

Capsule Summary: Alkyl polyglucoside surfactant was synthesized and characterized and overall, the surfactant is recommended for public and industrial usage due to its environmental friendliness.

Cite This Article As: C. Obi, P. V. Aliba and G. N. Iwuoha. Synthesis and characterization of alkyl polyglucoside surfactant: A pilot tool to industrial applications. Chemistry International 7(3) (2021) 172-180.

https://doi.org/10.5281/zenodo.4899464

\section{INTRODUCTION}

Surfactants are a diverse group of chemical species consisting of a polar, water soluble head group and a non-polar hydrocarbon tail group. Surfactants are best known for their solubility and cleaning properties which secured them a place among detergent and other cleaning products. Massive quantities of surfactants are being used in households and industries and most end up dispersed in the environment (Ana et al., 1997; Ivankovic et al., 2009). Surfactants are organic compounds, i.e., contain both water-insoluble and oil-soluble component. Surfactants diffuse in water and adsorb at interfaces between air and water or at the interface between oil and water, in the case where water is mixed with oil. The water-insoluble hydrophobic group may extend out of the water phase into the oil phase, while the water-soluble (hydrophilic) head group remains in the water phase (Anwar et al., 2012). The chemistry behind this surface-active agent is that when dissolved in water at low concentrations, surfactant molecules exist as monomers (individual entities) (Rosen, 2014). At higher concentration, surfactant molecules aggregate into micelles, lowering the system's free energy. This is the underlying principle behind the production of domestic and industrial detergents. More so, it extends to the formulation drugs and other drugs related products. 


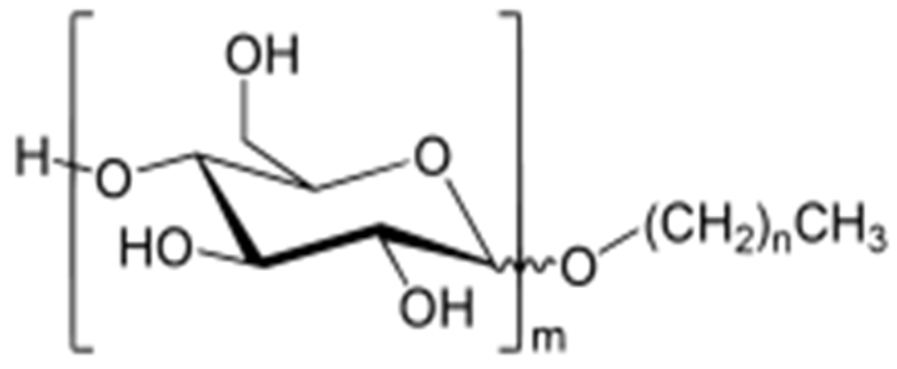

Fig. 1: General chemical structure of an alkyl polyglucoside. Where $\mathrm{m}$ is number of monomers.

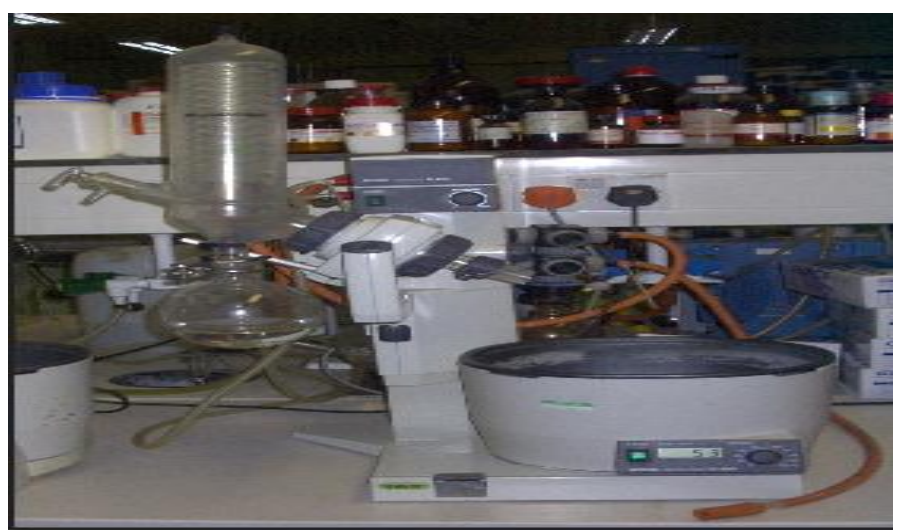

Fig. 2: Diagram of a rotatory evaporator

The threshold concentration at which this occurs is known as the critical micelle concentration (CMC) (Ball, 2003). The fundamental ability for a surfactant to form a micelle gives it their detergency and solubilisation properties. At concentrations above CMC, surfactants solubilize more hydrophobic organic compounds that would dissolve in water alone while in concentration below CMC it solubilizes hydrophilic organic compounds that may dissolve in lipid. Critical micelle concentration also seems to define surfactant's antibacterial properties (Cella et al., 2011) which demonstrated that surfactants with lower CMC exhibited higher germicidal activity. Surfactants may act as detergents, wetting agents, emulsifiers, foaming agent and dispersants.

Moreover, as the concentration of the surfactant increases, the molecules tend to associates to form aggregates. The aggregation which is formed is within a narrow concentration range thereby making some physical properties of the surfactant solution change abruptly (Eastoe, 2002). The aggregation numbers indicate how many molecules are present in an aggregate and often there will be a rather narrow size range in aqueous solutions, the hydrophobic tails of the surfactant associated with the head groups (hydrophilic) is exposed to the solvent. Although surfactants are often present in very small amounts in solution, they do affect the overall properties of the system greatly, such as surface tension, osmotic pressure, solubility, etc., because of their ability to adsorb at surfaces and to form micelles in the solutions (Goyal and Aswal, 2001). The transition from a monomeric solution to a aggregated form can be seen as a change in the slope of plots against surfactant concentration of many physical properties such as absorbance, conductivity, viscosity, osmotic pressure, density, polarity, specific heat, refractive index, solubilisation power, surface tension, etc. (Jean, 2002; Held, 2014). From all indication of several studies, it has been found that the much-studied surfactant found in many detergents is sodium dodecyl sulphate (SDS) which is easily hydrolysed to dodecanol and can be seen as a possible contaminant to the environment. The increasing awareness of surfactants' effects on the environment has caused increasing needs for more environmentally friendly cleaning products. As a response, chemical industries directed towards producing more eco-friendly surfactants which are derived from renewable resources (Noor et al., 2017). Most of these surfactants are non-ionic in nature.

These non-ionic surfactants are manufactured entirely from natural, renewable resources such as plant oils. They have great environmental compatibility and are highly biodegradable such as alkyl polyglucoside, which is a sugarbased surfactant.

Alkyl polyglucoside is a class of non-ionic surfactants and commonly referred to as APGs. It is an organic molecule used as a foaming agent, emulsifier, pharmaceutical granulating agents and cosmetic surfactant. It is water soluble with excellent adjuvant properties (Khan et al., 2012).

They are called "green surfactants" because they are very safe to the environment. APG is a brownish viscous liquid which is odourless. It is characterised by a hydrophilic saccharide unit and a hydrophobic alkyl chain. It is also used as additives which reduce motion resistance and wear relative to water. Methyl blue is a chemical compound with the molecular formula $\mathrm{C}_{37} \mathrm{H}_{27} \mathrm{~N}_{3} \mathrm{Na}_{2} \mathrm{O}_{9} \mathrm{~S}_{3}$. It is used in this study to enhance the determination of $\mathrm{CMC}$.

In households, non-ionic surfactants are used in laundry detergents and hard surface cleaners. Evaluation of the critical micelle concentration for ionic surfactants has been reported in several books and it is very imperative to determine the critical micelle concentration of non-ionic surfactants because of its wide applications.

Therefore, the aim of this study is to synthesize and evaluate the critical micelle concentration of non-ionic surfactant (alkyl polyglucosides) using UV-Visible Spectrophotometer.

\section{MATERIAL AND METHODS}

Synthesis and characterization of surfactant were carried out using Gas Chromatography-Mass Spectrophotometer and UVVisible spectrophotometer. Analytical grade reagents were used in this study.

\section{Synthesis of alkyl polyglucosides}


Table 1: Volume of stock added, concentration of stock solution and absorbance

\begin{tabular}{ccccc}
\hline Test tubes & Volume $(\mathrm{ml})$ of surfactant & Volume $(\mathrm{ml})$ of $\mathrm{H}_{2} \mathrm{O}$ & Conc. surfactant & Absorbance \\
\hline 1 & 0.25 & 2.25 & 0.02 & 0.115 \\
2 & 0.5 & 2 & 0.05 & 0.194 \\
3 & 0.75 & 1.75 & 0.09 & 0.139 \\
4 & 1 & 1.5 & 0.13 & 0.24 \\
5 & 1.25 & 1.25 & 0.2 & 0.443 \\
6 & 1.5 & 1 & 0.3 & 0.345 \\
7 & 1.75 & 0.75 & 0.47 & 0.216 \\
8 & 2 & 0.5 & 0.8 & 0.474 \\
9 & 2.25 & 0.25 & 1.80. & 0.514 \\
\hline
\end{tabular}

D-glucose (20 g) was added into $157.38 \mathrm{ml}$ of octanol. It was stirred to obtain a suspension of D-glucose in octanol. A $2.22 \mathrm{~g}$ of sulphamic acid was added as a catalyst and temperature increased to $80^{\circ} \mathrm{C}$. It was then stirred for 5 hours and the mixture was allowed to cool at room temperature. The solvent was extracted using rotatory evaporator. Due to the high boiling point $\left(195^{\circ} \mathrm{C}\right)$ of the solvent (octanol), rotatory evaporator was used in other for the product not to be destroyed with a low pressure of 25 Torr and a temperature of $80^{\circ} \mathrm{C}$. The product (alkyl polyglucoside) was obtained after the process of separation.

\section{Critical Micelle concentration}

Aqueous stock solution of $0.2 \mathrm{M}$ alkyl polyglucoside were prepared by dissolving $1.60 \mathrm{~g}$ in distilled water of $25 \mathrm{ml}$ mark of volumetric flask. Methyl blue dye was prepared by dissolving $1.95 \mathrm{~g}$ of solute in $25 \mathrm{ml}$ of $98.5 \%$ ethanol. Alkyl polyglucoside stock solution $(0.25 \mathrm{ml})$ was pipetted into 2.25 $\mathrm{ml}$ distilled water making a total of $2.5 \mathrm{ml}$. Methyl blue dye (23 drops) was added. The solution was place on a UV-Visible spectrophotometer and absorbance was recorded at $420 \mathrm{~nm}$. This step was repeated until all the serial solutions of APG have been added into the beaker. De-ionized water was used as a blank solution for the analysis. The critical micelle concentration (CMC) value was determined from the break point in the plot of absorbance (A) versus surfactant concentration. The $\mathrm{CMC}$ was measured in $\mathrm{mol} / \mathrm{dm}^{3}$.

\section{Determination of thermodynamic variables}

For non-ionic surfactant, the standard Gibbs free energy of micellization $\left(\Delta \mathrm{G}^{\mathrm{o}}\right.$ mic.) is obtained using Eq. 1 (Cheng et al., 2004).

$\Delta \mathrm{G}^{\mathrm{o}}$ mic. $=\mathrm{RT} \operatorname{In}[\mathrm{CMC}]$

Where, $\mathrm{R}=$ gas constant; $\mathrm{T}=$ absolute temperature; $[\mathrm{CMC}]=$ critical micelle concentration. The standard entropy of micellization $\left(\Delta \mathrm{S}^{\mathrm{o}}\right.$ mic.) is obtained using Eq. 2.

$\Delta \mathrm{S}^{\mathrm{o}}{ }_{\text {mic. }}=-\left[\frac{\delta \mathrm{G}^{\mathrm{o}}{ }_{\mathrm{mic}}}{\delta \mathrm{T}}\right]$
Then, the standard enthalpy of micellization $\left(\Delta \mathrm{H}^{\circ}\right.$ mic. $)$ is obtained using Eq. 3.

$\Delta \mathrm{H}_{\text {mic. }}=\Delta \mathrm{G}^{\mathrm{o}}$ mic. $+\mathrm{T} \Delta \mathrm{S}_{\text {mic. }}^{\mathrm{o}}$

\section{RESULTS AND DISCUSSION}

The mass spectrograph was complex given that the product was not just one but a mixture of different combinations. Consequently, the peaks were interpreted based on its mass to charge ratio $(\mathrm{m} / \mathrm{z})$.

\section{The peak at $\mathrm{m} / \mathrm{z}$ of 340}

This peak can be obtained by the combination below;

$$
\begin{aligned}
& \mathrm{C}_{6} \mathrm{H}_{12} \mathrm{O}_{6}+\mathrm{C}_{6} \mathrm{H}_{12} \mathrm{O}_{6} \rightarrow \mathrm{C}_{12} \mathrm{H}_{22} \mathrm{O}_{11}+\mathrm{H}_{2} \mathrm{O} \\
& \\
& 342 \stackrel{-}{\stackrel{-H_{2}}{\longrightarrow}} 340
\end{aligned}
$$

The peak at $\mathrm{m} / \mathrm{z}$ of 284

$$
340 \stackrel{-56}{2 C=O} \quad 284
$$

The peak at $\mathrm{m} / \mathrm{z}$ of 256

$$
340 \underset{\substack{\mathrm{ORC}_{2} \mathrm{CH} \\ \mathrm{OR}}}{-\frac{28}{\longrightarrow}} 312
$$

The peak at $\mathrm{m} / \mathrm{z}$ of 270

$$
284 \underset{\mathrm{CH}_{2}}{\stackrel{-14}{\longrightarrow}} 270
$$

The peak at $\mathrm{m} / \mathrm{z}$ of 312

$$
340 \underset{\mathrm{CH}_{2} \mathrm{CH}_{2}}{\stackrel{-28}{\longrightarrow}} 312
$$

The peak at $\mathrm{m} / \mathrm{z}$ of 242 

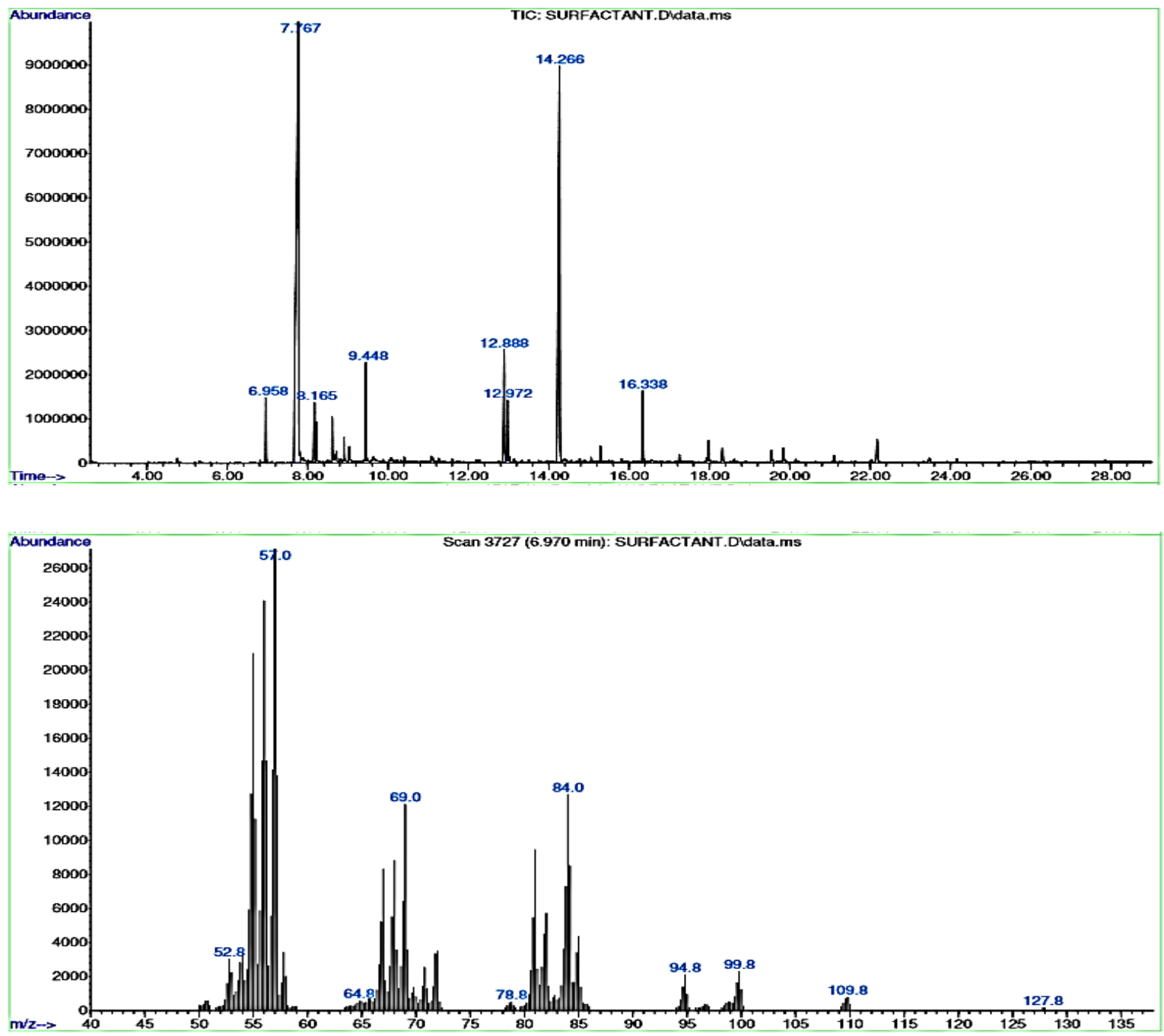

Fig. 3: Mass spectrum of alkyl polyglucoside

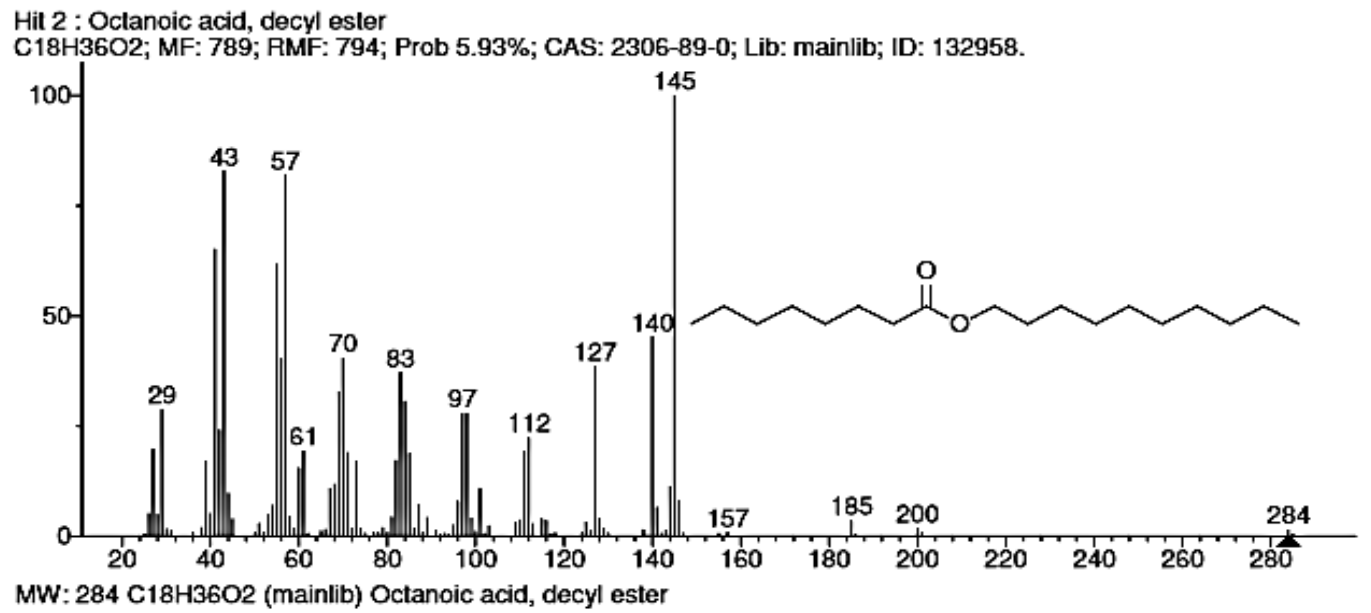

Fig. 4: Mass spectrum showing a peak at $\mathrm{m} / \mathrm{z}$ of 284 

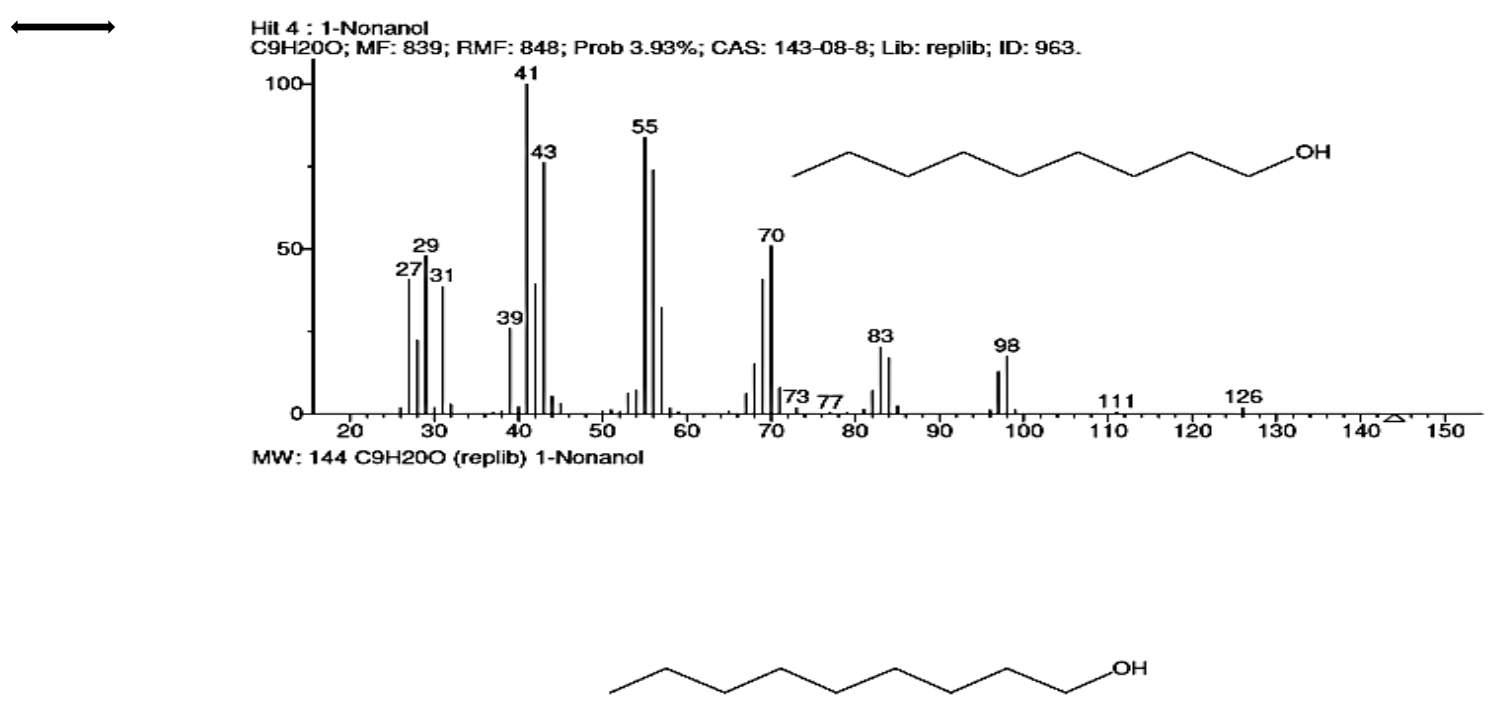

Fig. 11: Mass spectrum showing a peak at $\mathrm{m} / \mathrm{z}$ of 144

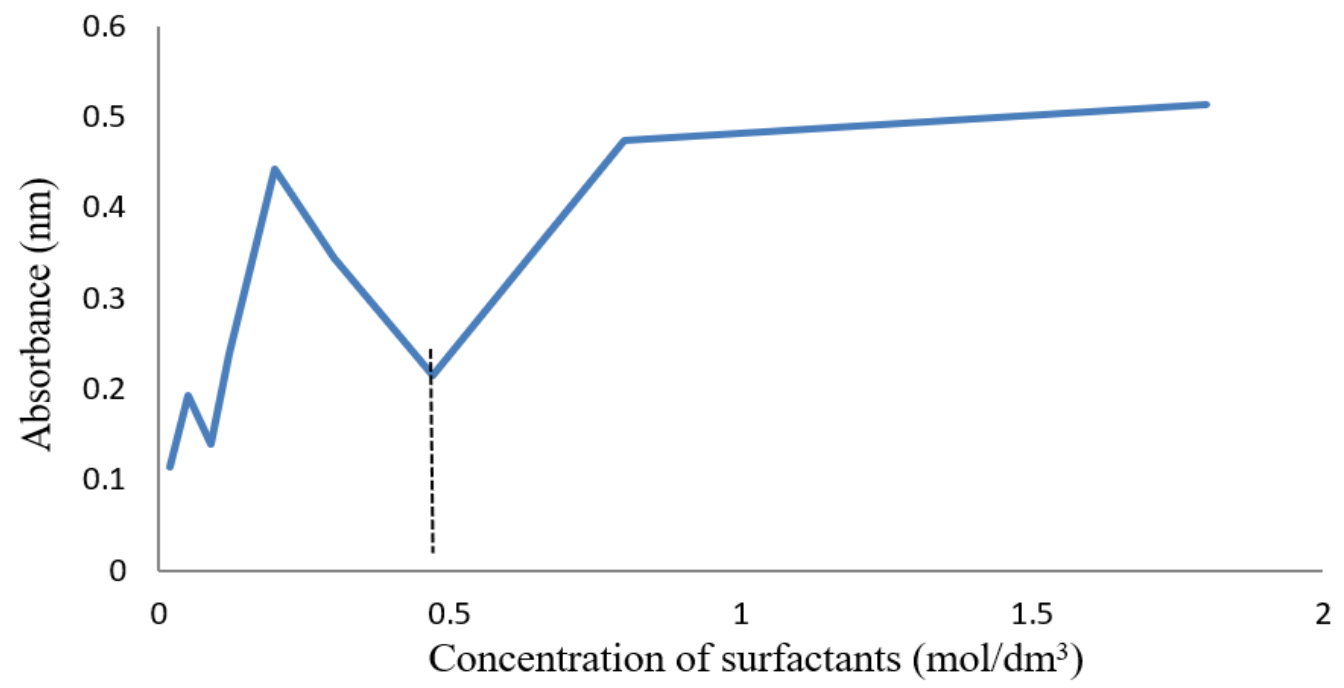

Fig. 12: Plot of absorbance as a function of alkyl polyglucoside surfactant concentration
$270 \frac{-28}{\mathrm{CH}_{2} \mathrm{CH}_{2}} \quad 242$
$368 \frac{-28}{\mathrm{CH}_{2} \mathrm{CH}_{2}} \quad 340$

The peak at $\mathrm{m} / \mathrm{z}$ of 368 can be obtained by the reaction below. The peak at $\mathrm{m} / \mathrm{z}$ of 112
$\mathrm{C}_{6} \mathrm{H}_{12} \mathrm{O}_{6}+2 \mathrm{C}_{8} \mathrm{H}_{17} \mathrm{O}_{\mathrm{H}} \rightarrow \mathrm{C}_{22} \mathrm{H}_{44} \mathrm{O}_{6}+2 \mathrm{H}_{2} \mathrm{O}$
$180 \mathrm{~g} \quad 2(130 \mathrm{~g}) \quad 404 \mathrm{~g} \quad 2(18 \mathrm{~g})$
$\mathrm{C}_{8} \mathrm{H}_{17} \mathrm{O}_{\mathrm{H}} \underset{18}{\stackrel{-\mathrm{H}_{2} \mathrm{O}}{18}} 112$

$404 \underset{36}{\stackrel{2 \mathrm{H}_{2} \mathrm{O}}{\longrightarrow}} 368$

The peak at $\mathrm{m} / \mathrm{z}$ of 340

The peak at $\mathrm{m} / \mathrm{z}$ of 98

$130 \mathrm{~g} \underset{\mathrm{CH}_{3} \mathrm{OH}}{\stackrel{-32}{\longrightarrow}} 98$ 

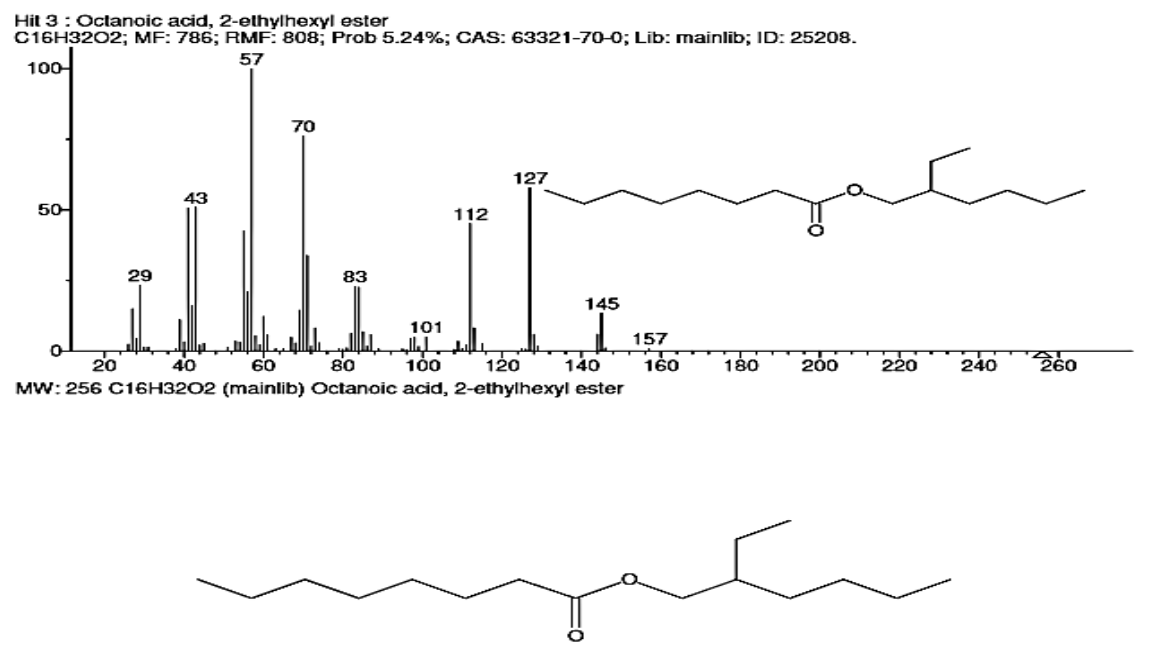

Fig. 5: Mass spectrum showing a peak at $\mathrm{m} / \mathrm{z}$ of 256
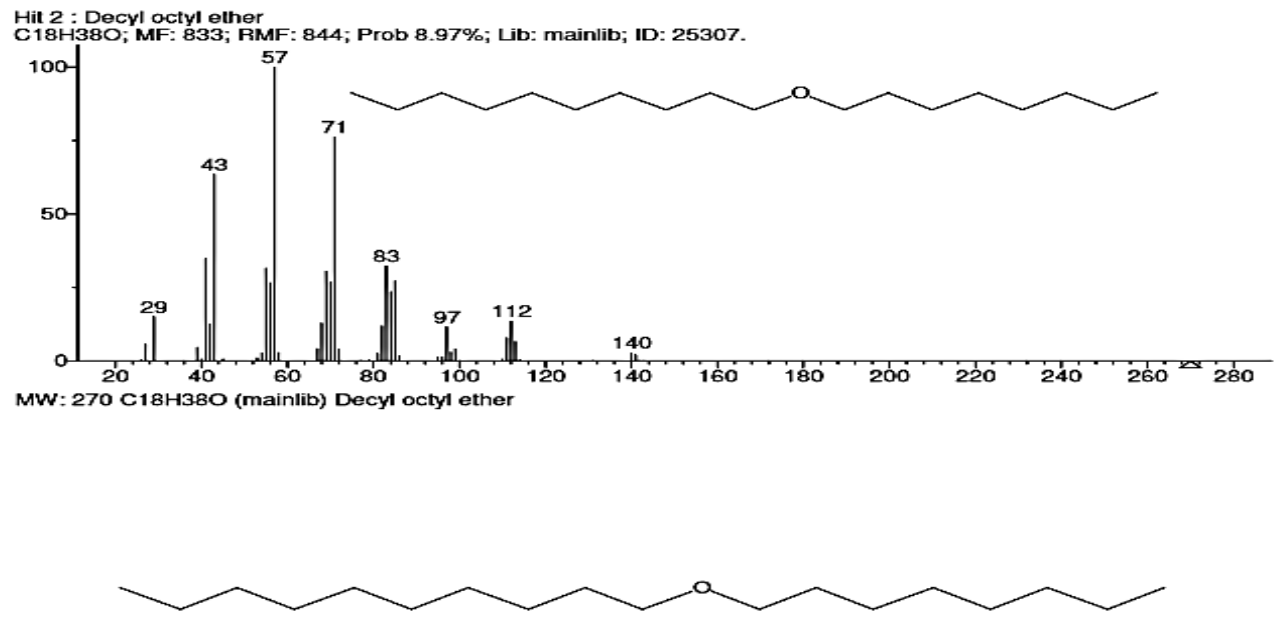

Fig. 6: Mass spectrum showing a peak at $\mathrm{m} / \mathrm{z}$ of 270

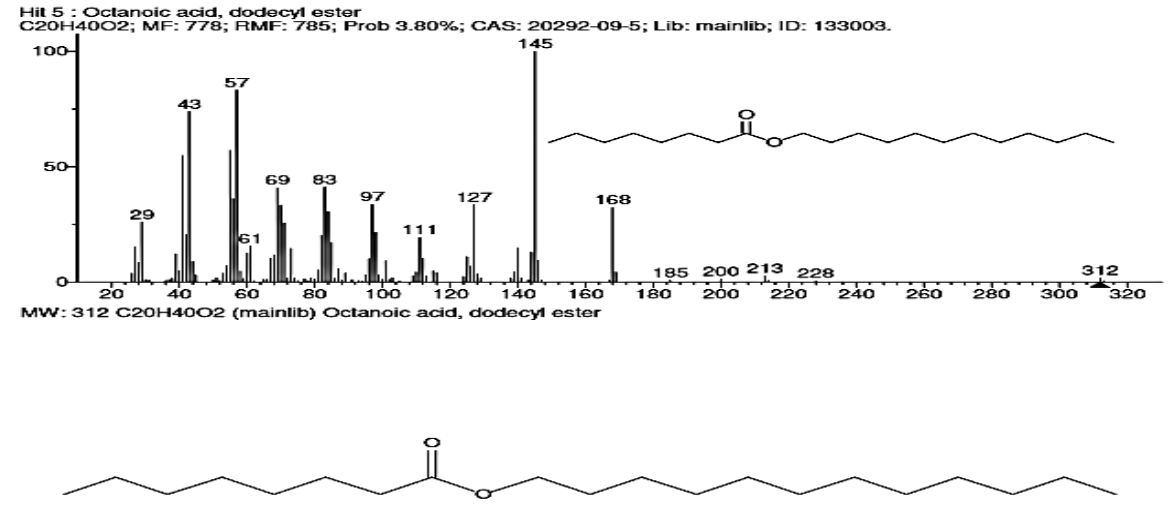

Fig. 7: Mass spectrum showing a peak at $\mathrm{m} / \mathrm{z}$ of 312 

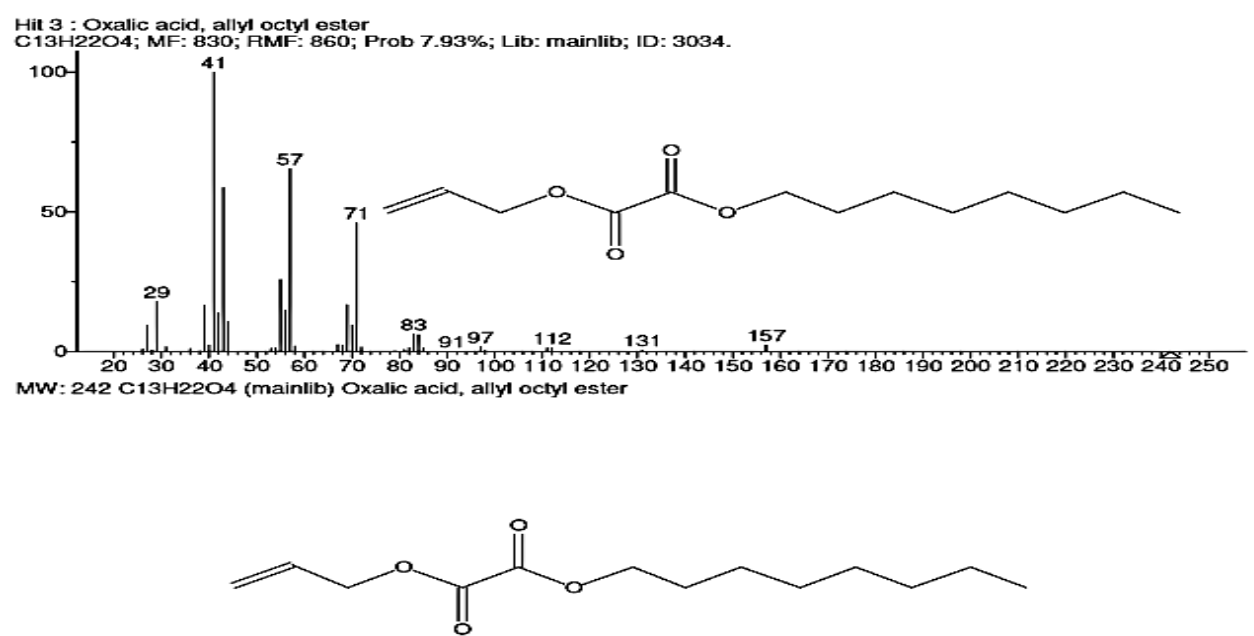

Fig. 8: Mass spectrum showing a peak at $\mathrm{m} / \mathrm{z}$ of 242
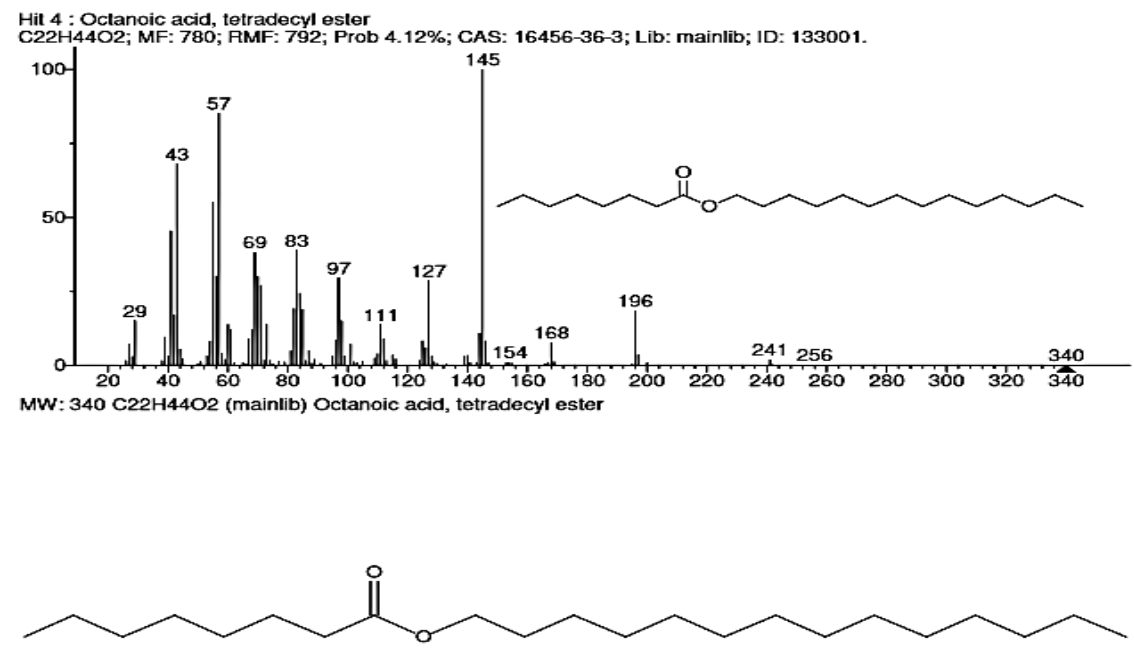

Fig. 9: Mass spectrum showing a peak at $\mathrm{m} / \mathrm{z}$ of 340

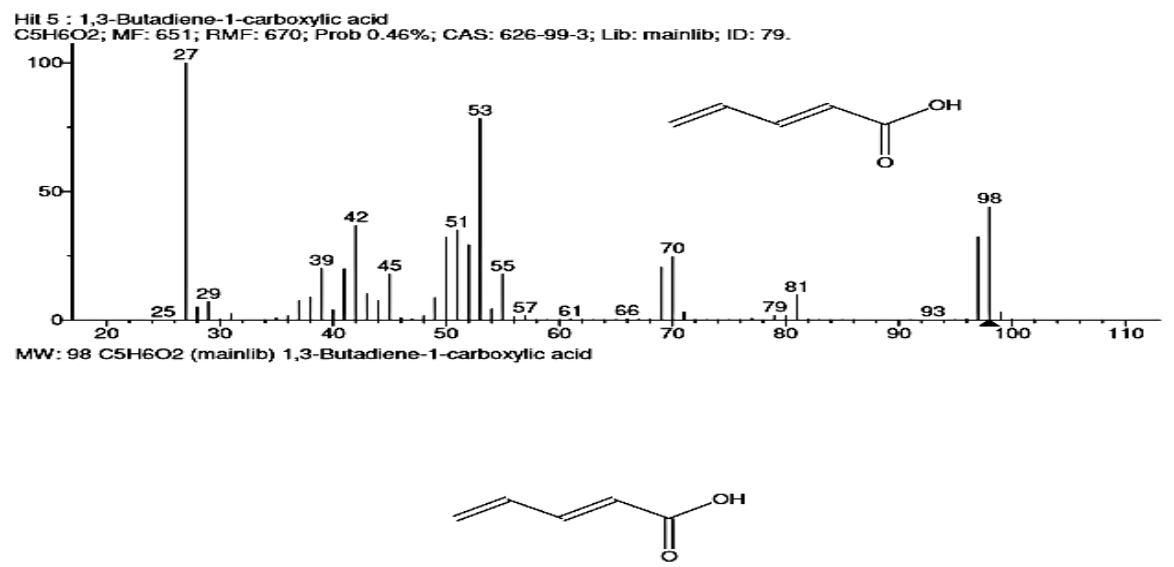

Fig. 10: Mass spectrum showing a peak at $\mathrm{m} / \mathrm{z}$ of 98 
The peak at $\mathrm{m} / \mathrm{z}$ of 144

$$
\mathrm{C}_{6} \mathrm{H}_{12} \mathrm{O}_{6} \underset{2 \mathrm{H}_{2} \mathrm{O}}{\stackrel{-36}{\longrightarrow}} 144 \mathrm{~g}
$$

The above results showed that APG was successfully synthesized using GCMS.

\section{Evaluation of the CMC of alkyl polyglucoside}

The surfactant absorbance was measured as a function of their concentration at a particular wavelength as shown in Table 1. The result showed clearly that at a concentration below the CMC, the solution absorbance was low. At CMC, there was a sudden increase in absorbance of the solution; this could be due to the formation of micelle. Above the CMC, the absorbance of the solution increased linearly with an increasing concentration, and later showed a decrease in absorbance. The CMC occurred where there was a sharp break or a sudden decrease in absorbance. The result revealed that the CMC of alkyl polyglucoside was found to be $0.50 \mathrm{~mol} / \mathrm{dm}^{3}$. The CMC obtained by absorbance showed a more actual value for the CMC of non-ionic surfactant, since the CMC of non-ionic surfactants are lower than that ionic surfactant (Nasiru et al., 2011).

The negative value of Gibbs free energy change $\left(\Delta \mathrm{G}^{\mathrm{o}}{ }_{\text {mic. }}=-1.716 \mathrm{~kJ} / \mathrm{mol}\right)$ showed that the process was spontaneous and feasible at $298 \mathrm{~K}$. The positive value of $\Delta \mathrm{S}^{\circ}$ mic $\left(+5.75 \times 10^{-3} \mathrm{~J} / \mathrm{mol}\right)$ could be due to high disorderliness associated with the removal of surfactant molecule from the aqueous phase. However, the small value of $\Delta \mathrm{H}^{\mathrm{o}}$ mic $(-1.7102$ $\mathrm{kJ} / \mathrm{mol}$ ) in this study was indicative of the fact that the attractive cohesive forces along hydrophobic chain was opposed by the strong interaction of the oxyethylene chain of APG with water (Owoyomi et al., 2011; Mahmood and AlKoofee, 2013). Hence, the developed method has potential for the preparation of alkyl polyglucoside for practical applications (Budi et al., 2010; Pantelic and Cuckovic, 2014; Terescenco et al., 2018; Wei et al., 2020).

\section{CONCLUSIONS}

The micellization behaviour of non-ionic surfactants (alkyl polyglucoside) was studied using UV-Visible Spectrophotometer. This study reveals that the use of UVVisible Spectroscopy technique was an accurate and easy way of determining the critical micelle concentration of non-ionic surfactants. The negative value of Gibbs free energy change of micellization $\left(\Delta \mathrm{G}^{\circ} \mathrm{CMC}\right)$ obtained showed that micellization process was spontaneous and the negative value of the $\Delta \mathrm{H}^{\circ} \mathrm{CMC}$ revealed the exothermic nature of the process. This study will find significant application in the process of emulsion polymerization and in the production of cosmetic products such as soaps, creams, etc. The surfactant applied in this study can also be used in pharmacology to improve the solubility of insoluble drugs for effective administration.

\section{REFERENCES}

Ana, D., Aurora, F., Noemí, G., Emilia I., Montenegro, L., 1997. Determination of Critical Micelle Concentration of Some Surfactants by Three Techniques, Journal of Chemical Education 74, 1227-1231

Anwar, A., Shadma T., Priyanka B., Vidiksha B., Nisar, A., 2012. Critical micelle concentration and self-aggregation of hexadecyltrimethylammonium bromide in aqueous glycine and glycylglycine solutions at different temperatures, Journal of Physical Chemistry 86, 19231929.

Ball, D.W., 2003. On the Adsorption of Counter-ions at the Surface of Detergent Micelles, Journal of Physical Chemistry 1, 7032.

Bibi I., Khan A., Rehman, N., Pervaiz S., Mahmood, K., Siddiq, M., 2012. Journal of Dispersion Science and Technology 33, 792.

Budi, S., Daud, A.R., Radiman, S., Umar, A.A., 2010. Effective electrodeposition of $\mathrm{Co}-\mathrm{Ni}-\mathrm{Cu}$ alloys nanoparticles in the presence of alkyl polyglucoside surfactant. Applied Surface Science 257, 1027-1033.

Cella, J.A., Harriman, L.A., Eggenberger, D.N., Harwood, H.J. 2011. The relationship of charge density, antibacterial activity and micelle formation of quaternary ammonium salts. Journal of Chemical Society 77, 4264-4266.

Cheng, H., Stenby, E.H., Kontogeorgis, G., 2004. Thermodynamic Modelling of Surfactant Solutions. Journal of Physical Chemistry 1, 1-2.

Eastoe, J., 2002. Surfactant Chemistry. Journal of Physical Chemistry 1, 34-50.

Goyal, P.S, Aswal, V.K., 2001. Micellar structure and Intermicelle interactions in micellar solutions. Journal of Small Angle Neutron Scattering Studies. Current Science 80, 972-979

Held, P., 2014. Rapid Critical Micelle Concentration (CMC) Determination Using Fluorescence Polarization. Journal of Analysis of the Physical-Chemical Properties of Detergents 888, 451-5171.

Ivanković, T., Hrenović, J., 2010. Surfactants in the Environment. Journal in Archives of Industrial Hygiene and Toxicology 61, 95-110.

Jean, L., 2002. Surfactants-Types and Uses. Journal on Teaching Aid in Surfactant Science \& Engineering 2, 300.

Khan, Z., AL-Thabaiti, S.A., Obaid, A.Y., Khan, Z.A., Al-Youbi, A., 2012. Shape-directing role of cetyltrimethylammonium bromide in the preparation of silver nanoparticles. Journal of Colloid and Interface Science 367, 101-108.

Mahmood, M.E., Al-Koofee, D.A.F., 2013. Effect of Temperature changes on CMC for Tween series surfactant. Global Journal of Science Frontier Research Chemistry 13, 1-7.

Nasiru, T., Avila, L., Levine, M., 2011. Determination of Critical Micelle Concentrations Using UV-Visible Spectroscopy. Journal of High School 2, 1.

Noor, R., Hidayat,U., Sultan, A., Jan, A., Khan, S., Tariq, M., 2017. Surface and thermodynamic study of micellization of nonionic surfactant/diblock copolymer system as revealed by 
surface tension and conductivity. Journal of Materials and Environmental Sciences (4), 1161-1167

Owoyomi, O., Ige. J., Soriyan, O., 2011. Thermodynamics of Micellization of $n$-Alkyltriphenylphosphonium Bromides: A Conductometric Study. Journal of Chemical Sciences 5, 25-31.

Pantelic, I., Cuckovic, B., 2014. 1 - Alkyl Polyglucosides: An emerging class of sugar surfactants, in: Pantelic, I. (Ed.), Alkyl Polyglucosides. Woodhead Publishing, Oxford, pp. 119.

Rosen, J. M., 2004. Surfactants and Interfacial Phenomena. Journal of Colloid and Interface Science 24, 1197-1284.

Terescenco, D., Savary, G., Clemenceau, F., Merat, E., Duchemin, B., Grisel, M., Picard, C., 2018. The alkyl polyglucoside/fatty alcohol ratio effect on the formation of liquid crystal phases in binary systems. Journal of Molecular Liquids 253, 45-52.

Wei, P., Li, J., Xie, Y., Huang, X., Sun, L., 2020. Alkyl polyglucosides for potential application in oil recovery process: Adsorption behavior in sandstones under high temperature and salinity. Journal of Petroleum Science and Engineering 189, 107057.

Visit us at: http://bosaljournals.com/chemint/

Submissions are accepted at: editorci@bosaljournals.com 